\title{
The viral hypothesis: how herpesviruses may contribute to Alzheimer's disease
}

\author{
Michael Wainberg ${ }^{1} \cdot$ Tain Luquez $^{1} \cdot$ David M. Koelle $^{2,3,4,5,6} \cdot$ Ben Readhead $^{7} \cdot$ Christine Johnston $^{2,3,6} \cdot$ \\ Martin Darvas $^{6} \cdot$ Cory C. Funk $\mathbb{B}^{1}$
}

Received: 14 December 2020 / Revised: 12 April 2021 / Accepted: 19 April 2021 / Published online: 10 May 2021

(c) The Author(s) 2021. This article is published with open access

\begin{abstract}
The hypothesis that infectious agents, particularly herpesviruses, contribute to Alzheimer's disease (AD) pathogenesis has been investigated for decades but has long engendered controversy. In the past 3 years, several studies in mouse models, human tissue models, and population cohorts have reignited interest in this hypothesis. Collectively, these studies suggest that many of the hallmarks of $\mathrm{AD}$, like amyloid beta production and neuroinflammation, can arise as a protective response to acute infection that becomes maladaptive in the case of chronic infection. We place this work in its historical context and explore its etiological implications.
\end{abstract}

\section{Background}

Nine herpesviruses infect humans, all of which establish lifelong latency after infection. It has long been known that several herpesviruses, including herpes simplex virus-1 (HSV-1), establish latency in the peripheral nervous system. However, it was only with the advent of polymerase chain reaction (PCR) amplification that researchers discovered, in 1991, that trace amounts of HSV-1 DNA were also present in the brains of both $\mathrm{AD}$ patients and healthy controls [1], a finding since extended

These authors contributed equally: Michael Wainberg, Tain Luquez

Cory C. Funk

cory.funk@isbscience.org

1 Institute for Systems Biology, Seattle, WA, USA

2 Department of Medicine, University of Washington, Seattle, WA, USA

3 Vaccine and Infectious Disease Division, Fred Hutchinson Cancer Research Center, Seattle, WA, USA

4 Department of Global Health, University of Washington, Seattle, WA, USA

5 Benaroya Research Institute, Seattle, WA, USA

6 Department of Laboratory Medicine and Pathology, University of Washington, Seattle, WA, USA

7 Arizona State University-Banner Neurodegenerative Disease Research Center, Arizona State University, Tempe, AZ, USA to several other herpesviruses. While the significance of this discovery was initially unclear, more recent studies from 2007 to 2014 identified multiple links between herpesviral brain infection and pathological hallmarks of $\mathrm{AD}$ (Table 1).

Early efforts aimed to identify a relationship between herpes infection and amyloid beta (A $\beta)$. Wozniak et al. [2] reported in 2007 that HSV-1 directly induced intracellular and extracellular $A \beta$ production in cultured neuronal, glial cells and in wild-type mice by upregulating the $A \beta$-producing enzymes $\beta$-secretase 1 and $\gamma$-secretase. In 2009, Wozniak et al. [3] extended this observation by showing that HSV-1 DNA was present in $90 \%$ of $\mathrm{A} \beta$ plaques in postmortem brains from AD patients, and that $72 \%$ of HSV-1 DNA in the brain was found within these plaques. In 2008, a study by Zambrano et al. [4] found that HSV-1 infection of mouse neuronal cultures caused another hallmark of $\mathrm{AD}$, tau hyperphosphorylation. In 2014, Bourgade et al. [5] demonstrated that $\mathrm{A} \beta$ peptides could inhibit HSV-1 replication and viral entry. This mirrored previous observations where $A \beta$ was shown to have broad-spectrum antibacterial and antifungal activity [6]. Despite this evidence, the mechanistic connections between viral infection, $\mathrm{AD}$ genetic risk factors like $A P O E 4$, and $\mathrm{AD}$ etiology remained unclear.

\section{Main body}

In 2018, Eimer et al. [7] reported two observations supporting a protective role for $A \beta$ against herpesviruses. They 
Table 1 Selected studies consistent with a contributory role of herpesviral infections to AD.

Study Conclusions

Latent herpes simplex virus type 1 in normal and Alzheimer's disease brains (Jamieson et al., J Med Virol. 1991 [1])

Herpes simplex virus infection causes cellular $\beta$-amyloid accumulation and secretase upregulation (Wozniak et al., Neurosci Lett. 2007 [2])

Neuronal cytoskeletal dynamic modification and neurodegeneration induced by infection with herpes simplex virus type 1 (Zambrano et al., J Alzheimers Dis. 2008 [4])

Herpes simplex virus type 1 DNA is located within Alzheimer's disease amyloid plaques (Wozniak et al., J Pathol. 2009 [3])

$\beta$-Amyloid peptides display protective activity against the human Alzheimer's disease-associated herpes simplex virus-1 (Bourgade et al., Biogerontology. 2015 [5])

Alzheimer's disease-associated $\beta$-amyloid is rapidly seeded by Herpesviridae to protect against brain infection (Eimer et al., Neuron. 2018 [7])

Multiscale analysis of three independent Alzheimer's cohorts reveals disruption of molecular, genetic, and clinical networks by Human herpesvirus (Readhead et al., Neuron. 2018 [9])

The innate immunity protein IFITM3 modulates $\gamma$-secretase in Alzheimer's disease (Hur et al., Nature. 2020 [15])

A 3D human brain-like tissue model of herpes-induced Alzheimer's disease (Cairns et al., Sci Adv. 2020 [13])

Interaction between APOE 4 and herpes simplex virus type 1 in Alzheimer's disease (Linard et al., Alzheimers Dement. 2020 [21])
HSV-1 DNA is present in the brains of the majority of both normal and AD patients.

HSV-1 induces A $\beta$ production and secretion in cultured neuronal and glial cells and wild-type mice by upregulating the $A \beta$-producing enzymes $\beta$-secretase 1 and $\gamma$-secretase.

HSV-1 infection causes tau hyperphosphorylation in mouse neuronal cultures.

HSV-1 DNA is present in the core of $90 \%$ of $A \beta$ plaques in postmortem brains from AD patients, and $72 \%$ of HSV-1 DNA in the brain was found within these plaques.

$\mathrm{A} \beta$ inhibits HSV-1 replication and viral entry in cell cultures.

Amyloid- $\beta$ plaques form to entrap viruses in $5 \mathrm{xFAD}$ mice and are protective against herpes simplex encephalitis in 3D human neural cells.

Increased HSV-1, HHV-6A, and HHV-7 viral RNA levels detected in postmortem brain samples of $\mathrm{AD}$ patients relative to controls.

Herpesviruses predicted to modulate the expression of known ADrelated genes.

Interferon- $\gamma$ treatment induced $\mathrm{A} \beta$ production in mouse neural cultures. IFITM3, a target of interferon signaling, physically interacts with $\gamma$ secretase and IFITM3 knockout impairs A $\beta$ production in $5 \mathrm{xFAD}$ mice.

HSV-1 infection of a 3D brain tissue model led to the formation of $A \beta$ plaque-like structures, tau hyperphosphorylation, astrogliosis, neuroinflammation, and disrupted neuronal electrical activity. The antiherpetic drug valacyclovir prevented these changes.

APOE4 carriers with recent $\mathrm{HSV}-1$ reactivation $(\mathrm{IgG}+$ and $\mathrm{IgM}+$, or elevated $\mathrm{IgG}$ ) developed $\mathrm{AD}$ at about $3 \times$ the rate of those merely infected with HSV-1 (IgG+); APOE4 noncarriers showed no such association. This indicates a gene-by-environment interaction between APOE4 and HSV-1 reactivation on AD risk. found that 5xFAD mice (which overexpress variants of human APP and PSEN1 containing five AD-linked causative mutations) survived encephalitis from intracranial HSV-1 injection better than wild-type mice. They also found that $\mathrm{A} \beta$ binds HSV-1 and HHV-6 surface glycoproteins-consistent with Cribbs et al. and Bourgade et al.'s observations that $\mathrm{A} \beta$ has sequence homology with HSV-1 glycoprotein B [5, 8]—and forms clumps that entrap viral particles. The authors hypothesized that $\mathrm{A} \beta$ deposition might protect against acute infection in the short term, but contribute to plaque formation over the long term in the case of chronic, low-grade infection.

Also in 2018, Readhead et al. [9] analyzed postmortem brain RNA-seq data from three cohorts and found evidence that herpesviruses modulate the expression of AD-related genes in AD patients' brains. First, they found that RNA levels (a proxy for viral abundance) of three herpesviruses, HSV-1, HHV-6A, and HHV-7, were consistently increased in $\mathrm{AD}$ cases relative to controls. Second, they found genetic variants associated with viral RNA levels and used them to predict which viruses might alter the expression of host genes, and vice versa. Three herpesviruses were predicted to perturb host gene expression across all surveyed brain regions: HSV-1, HSV-2, and HHV-6A. Strikingly, the host genes most consistently associated with these viruses included many genes linked to $\mathrm{A} \beta$ production and/or $\mathrm{AD}$ risk. For instance, HHV-6A was associated with BACE1 (which encodes $\beta$-secretase 1) and PSENI (which encodes a subunit of $\gamma$-secretase), as well as BIN1, CLU, and PICALM - genes associated with $\mathrm{AD}$ in genome-wide association studies (GWAS). The most-associated genes also included those involved in innate immunity and antiviral sensing. These results generated some controversy, with a subsequent study [10] noting that Readhead et al. also reported reads mapping to hepatitis $\mathrm{C}$ and variola (smallpox) virus in nearly $100 \%$ of brain samples from one American cohorteven though hepatitis C infects under 1\% of Americans [11] and variola virus was eradicated in the 1970s-perhaps due 
to sequence homology with other viruses or genomically integrated transposable elements. Despite these false positives, neither hepatitis $\mathrm{C}$ nor variola virus emerged as $\mathrm{AD}$ relevant species from the authors' integrative analysis. Another analysis of the same cohorts [12] found similar HHV-6A and HHV-7 levels in AD cases and controls, though this negative result is difficult to interpret since this analysis only detected HHV-6A DNA or RNA in $<1 \%$ of brain samples-over an order of magnitude less than both Readhead et al. and prior studies of other cohorts.

While many previous studies of herpesvirus infection and $\mathrm{AD}$ used primary culture or animal models, it remained unclear whether similar effects would be observed in more complex human tissue models. In 2020, Cairns et al. [13] approached this question with $3 \mathrm{D}$ brain organoids made of silk sponges infused with induced human neural stem cells, which spontaneously differentiate into a variety of neuronal and glial subtypes. HSV-1 infection of this human tissue model elicited $\mathrm{AD}$ hallmarks like $\mathrm{A} \beta$ plaque-like formations containing hyperphosphorylated tau, gliosis, neuroinflammation, decreased local field potential (indicative of disrupted neurotransmission), and neuronal death. Just like in a previous cell culture study [14], the antiherpetic drug valacyclovir largely rescued these changes, with early administration (same day as HSV-1 infection) more effective than later (1 day post-infection). Thus, HSV-1 infection was sufficient to induce AD-like pathophysiology in a human tissue model, and this was largely preventable by timely administration of an anti-herpes drug. This study provides perhaps the most compelling evidence to date for a contributory role of HSV-1 to AD.

Also in 2020, Hur et al. [15] reported that interferons, key signaling proteins of the innate immune system's antiviral response, can induce $\mathrm{A} \beta$ production. Treatment with interferon- $\gamma$ led to a $\sim 70 \%$ increase in $\mathrm{A} \beta$ secretion from mouse primary neurons. They also showed that interferon-induced transmembrane protein 3 (IFITM3), a target of interferon signaling, physically interacts with $\gamma$ secretase and that Ifitm 3 knockout impairs $\mathrm{A} \beta$ production. Another 2020 study by Roy et al. [16] reported an interaction in the opposite direction, finding that $A \beta$ fibrils containing nucleic acids (but not those without) could elicit a type I interferon response from mouse microglia. These studies suggest that herpesvirus-induced interferon signaling could accelerate $A \beta$ deposition, and that viral nucleic acids entrapped by $A \beta$ could trigger further interferon signaling, potentially leading to a positive feedback loop.

An emerging area of interest with respect to both herpesvirus infection and $\mathrm{AD}$ is the adaptive immune system. AD GWAS have implicated the HLA class II region, which is primarily involved in adaptive immunity. One potential mechanism that could mediate this association is herpesviral reactivation. Herpesviruses lie latent in the periphery and are kept in check by the adaptive immune system, so adaptive immune function could influence the frequency and/or intensity of viral reactivation and spread to the central nervous system (CNS). In 2020, Gate et al. [17] found greater clonal expansion of $\mathrm{CD} 8+\mathrm{T}$ cells with epitope specificity for Epstein-Barr virus in the cerebrospinal fluid of $\mathrm{AD}$ patients compared to healthy controls, suggesting a greater adaptive immune response against this herpesvirus in the CNS. Future work is necessary to determine what etiological consequences, if any, this may have for AD.

Further supporting a potential role for herpesviral reactivation in $\mathrm{AD}$ pathophysiology, a 2019 study from De Chiara et al. [18] showed that wild-type mice infected with HSV-1 developed $\mathrm{A} \beta$ accumulation, tau hyperphosphorylation, and neuroinflammation after several cycles of reactivation with thermal stress ( $15 \mathrm{~min}$ in a $43{ }^{\circ} \mathrm{C}$ water bath) compared to controls exposed to the thermal stress but not infected with HSV-1. Seven reactivation cycles produced more of the proinflammatory cytokines IL- 6 and IL- $1 \beta$ than three cycles. Mice subjected to more than seven reactivation cycles had irreversible cognitive deficits. A limitation of this study is that the authors did not demonstrate that the observed pathology was due to reactivation rather than initial infection.

Many population studies have found associations between AD and HSV-1 diagnosis [19] or reactivation [20]. For instance, a 2018 Taiwanese insurance claims study [19] reported that HSV diagnosis predicted a 2.5-fold higher rate of subsequent dementia diagnosis, but not among those prescribed antiherpetic drugs. However, these studies were purely epidemiological in nature and thus potentially subject to confounding. In 2020, Linard et al. [21] used a more robust gene-by-environment interaction study design to find that APOE4 carriers with recent $\mathrm{HSV}-1$ reactivation ( $\mathrm{IgG}+$ and $\mathrm{IgM}+$, or elevated $\mathrm{IgG}$ ) developed $\mathrm{AD}$ at $\sim 3 \times$ the rate of those merely infected with HSV-1 (IgG+); APOE4 noncarriers showed no such association. This suggests that APOE4 may increase the harmful effects of HSV-1 reactivation on $\mathrm{AD}$ risk, perhaps by increasing brain viral titers as it does in mice [22]. This study builds on results from the late 1990s [23, 24] that relied on postmortem HSV-1 PCR positivity in brain instead of antemortem seropositivity, which had the disadvantages of very small sample size, non-longitudinal designs, and lack of consistent replication $[25,26]$. It also builds on more recent studies showing geneby-environment interactions between APOE4 and HSV-1 seropositivity [27] and interactions between APOE genotype and HSV-1 neuroinvasiveness and latent viral load in mice [22]. A limitation of both Linard et al. and earlier gene-by-environment interaction studies is lack of correction for population structure (i.e., some pairs of individuals being more genetically similar to each other than others, 
even within a relatively homogeneous population), a common confounder in genetic association analyses [28].

\section{Conclusions}

While herpesviruses have been argued to contribute to $\mathrm{AD}$ for decades, recent studies have rekindled the debate. Collectively, these studies suggest that (1) A $\beta$ aggregation is a protective mechanism to entrap herpesviruses (and perhaps other pathogens), (2) herpesviruses trigger the main hallmarks of $\mathrm{AD}$ in human brain tissue models, (3) herpesvirus-induced interferon signaling can trigger $A \beta$ production, and (4) APOE4 increases the effect of herpesviral reactivation on AD risk. Strikingly, herpesviruses appear to be intimately related to both the largest genetic risk factor for $\mathrm{AD}$ (APOE4) and its most classic hallmarks $(\mathrm{A} \beta$ and tau).

The extent to which herpesviruses causally contribute to $\mathrm{AD}$ remains unclear. Certainly, herpesviruses are not the sole contributor: $\mathrm{AD}$ is a multifactorial disease with many contributory genetic and environmental factors (including, potentially, other pathogens [29]). Herpesviruses may only causally contribute to a minority of AD cases, and even then the effect size of this causal contribution may depend on the presence or absence of other risk factors.

Viewed another way, the causal effect size of these other risk factors may depend on the presence or absence of herpesviruses. Environmental factors like stress, diet, sleep, and exercise may influence AD risk in part by modulating the innate and adaptive immune responses to herpesviruses. As for genetic risk factors, the gene-by-environment interaction studies discussed here suggest that HSV-1 influences the amount of $\mathrm{AD}$ risk conferred by APOE4. The same may be true for other $\mathrm{AD}$ genetic factors like the protective G78R variant of PILRA [30], a co-receptor for HSV-1 entry [31]. A similar phenomenon has been observed in a mouse model of a Mendelian form of Parkinson's: Pinkl knockout mice did not develop Parkinson's symptoms unless inoculated with Gram-negative bacteria [32]. If not for herpesviruses, certain AD GWAS hits might have smaller effect sizes, or even disappear.

It is worth reflecting on what future evidence might strengthen or refute the contributory hypothesis of herpesvirus infections in $\mathrm{AD}$. So far, arguably the strongest evidence comes from perturbational studies showing that herpesvirus infection causes hallmarks of AD. Perturbational studies avoid the issues of confounding and reverse causality that plague associative or epidemiological studies, but have so far relied on animal and in vitro models. These models are imperfect representations of AD: for instance, animal models are often based on mutations in a single gene or disease pathway, even the best in vitro models fail to capture the structural intricacies of the human brain and its interactions with the periphery, and both types of models have difficulty capturing inter-individual variability and environmental contributors to AD risk. Fortunately, one sort of human perturbational study is ongoing: two randomized control trials of whether valacyclovir delays progression in HSV + AD patients (NCT03282916 and NCT02997982 at ClinicalTrials.gov). A positive result from these trials would further strengthen the evidence for the contributory hypothesis as well as confirming its clinical relevance. However, a negative result would not necessarily refute the hypothesis: by the time individuals develop symptomatic $\mathrm{AD}$, antiherpetics may already be "too little too late" [33]. Clinical trials of whether antiherpetics can reduce $\mathrm{AD}$ incidence among HSV-1-seropositive individuals with mild cognitive impairment-and particularly those who also have the APOE4 allele-might provide a more definitive answer [34].

Collectively, the studies summarized here provide interlocking evidence for a contributory role for herpesviruses to $\mathrm{AD}$, in conjunction with established etiological factors. Fundamentally, they support the model articulated by Eimer et al. in which the host's rational response to acute infection or reactivation- $\mathrm{A} \beta$ production for viral entrapment and neuroinflammation for viral clearance-becomes maladaptive in the case of chronic infection.

Funding This work was supported by grant R01-AG062514-02 from the National Institutes of Health.

\section{Compliance with ethical standards}

Conflict of interest The authors declare no competing interests.

Publisher's note Springer Nature remains neutral with regard to jurisdictional claims in published maps and institutional affiliations.

Open Access This article is licensed under a Creative Commons Attribution 4.0 International License, which permits use, sharing, adaptation, distribution and reproduction in any medium or format, as long as you give appropriate credit to the original author(s) and the source, provide a link to the Creative Commons license, and indicate if changes were made. The images or other third party material in this article are included in the article's Creative Commons license, unless indicated otherwise in a credit line to the material. If material is not included in the article's Creative Commons license and your intended use is not permitted by statutory regulation or exceeds the permitted use, you will need to obtain permission directly from the copyright holder. To view a copy of this license, visit http://creativecommons. org/licenses/by/4.0/.

\section{References}

1. Jamieson GA, Maitland NJ, Wilcock GK, Craske J, Itzhaki RF. Latent herpes simplex virus type 1 in normal and Alzheimer's disease brains. J Med Virol. 1991;33:224-7. 
2. Wozniak MA, Itzhaki RF, Shipley SJ, Dobson CB. Herpes simplex virus infection causes cellular $\beta$-amyloid accumulation and secretase upregulation. Neurosci Lett. 2007;429:95-100.

3. Wozniak MA, Mee AP, Itzhaki RF. Herpes simplex virus type 1 DNA is located within Alzheimer's disease amyloid plaques. J Pathol. 2009;217:131-8.

4. Zambrano A, Solis L, Salvadores N, Cortés M, Lerchundi R, Otth C. Neuronal cytoskeletal dynamic modification and neurodegeneration induced by infection with herpes simplex virus type 1 . J Alzheimers Dis. 2008;14:259-69.

5. Bourgade K, Garneau H, Giroux G, Le Page AY, Bocti C, Dupuis $\mathrm{G}$, et al. $\beta$-Amyloid peptides display protective activity against the human Alzheimer's disease-associated herpes simplex virus-1. Biogerontology. 2015;16:85-98.

6. Soscia SJ, Kirby JE, Washicosky KJ, Tucker SM, Ingelsson M, Hyman B, et al. The Alzheimer's disease-associated amyloid betaprotein is an antimicrobial peptide. PLoS ONE. 2010;5:e9505.

7. Eimer WA, Kumar DKV, Shanmugam NKN, Rodriguez AS, Mitchell T, Washicosky KJ, et al. Alzheimer's disease-associated $\beta$-amyloid is rapidly seeded by Herpesviridae to protect against brain infection. Neuron. 2018;99:56-63.e3.

8. Cribbs DH, Azizeh BY, Cotman CW, LaFerla FM. Fibril formation and neurotoxicity by a herpes simplex virus glycoprotein B fragment with homology to the Alzheimer's A beta peptide. Biochemistry. 2000;39:5988-94.

9. Readhead B, Haure-Mirande J-V, Funk CC, Richards MA, Shannon P, Haroutunian V, et al. Multiscale analysis of independent Alzheimer's cohorts finds disruption of molecular, genetic, and clinical networks by human herpesvirus. Neuron. 2018;99:64-82. e7

10. Chorlton SD. Reanalysis of Alzheimer's brain sequencing data reveals absence of purported HHV6A and HHV7. J Bioinform Comput Biol. 2020;18:2050012.

11. Rosenberg ES, Rosenthal EM, Hall EW, Barker L, Hofmeister MG, Sullivan PS, et al. Prevalence of hepatitis $C$ virus infection in US states and the District of Columbia, 2013 to 2016. JAMA Netw Open. 2018;1:e186371.

12. Allnutt MA, Johnson K, Bennett DA, Connor SM, Troncoso JC, Pletnikova O, et al. Human herpesvirus 6 detection in Alzheimer's disease cases and controls across multiple cohorts. Neuron. 2020;105:1027-35.e2.

13. Cairns DM, Rouleau N, Parker RN, Walsh KG, Gehrke L, Kaplan DL. A 3D human brain-like tissue model of herpes-induced Alzheimer's disease. Sci Adv. 2020;6:eaay8828.

14. Wozniak MA, Frost AL, Preston CM, Itzhaki RF. Antivirals reduce the formation of key Alzheimer's disease molecules in cell cultures acutely infected with herpes simplex virus type 1 . PLoS ONE. 2011;6:e25152.

15. Hur J-Y, Frost GR, Wu X, Crump C, Pan SJ, Wong E, et al. The innate immunity protein IFITM3 modulates $\gamma$-secretase in Alzheimer's disease. Nature. 2020;586:735-40.

16. Roy ER, Wang B, Wan Y-W, Chiu G, Cole A, Yin Z, et al. Type I interferon response drives neuroinflammation and synapse loss in Alzheimer disease. J Clin Invest. 2020;130:1912-30.

17. Gate D, Saligrama N, Leventhal O, Yang AC, Unger MS, Middeldorp $\mathrm{J}$, et al. Clonally expanded CD8 $\mathrm{T}$ cells patrol the cerebrospinal fluid in Alzheimer's disease. Nature. 2020;577: 399-404.

18. De Chiara G, Piacentini R, Fabiani M, Mastrodonato A, Marcocci ME, Limongi D, et al. Recurrent herpes simplex virus-1 infection induces hallmarks of neurodegeneration and cognitive deficits in mice. PLoS Pathog. 2019;15:e1007617.

19. Tzeng N-S, Chung C-H, Lin F-H, Chiang C-P, Yeh C-B, Huang $\mathrm{S}-\mathrm{Y}$, et al. Anti-herpetic medications and reduced risk of dementia in patients with herpes simplex virus infections-a Nationwide, Population-Based Cohort Study in Taiwan. Neurotherapeutics. 2018;15:417-29.

20. Lövheim H, Gilthorpe J, Adolfsson R, Nilsson L-G, Elgh F. Reactivated herpes simplex infection increases the risk of Alzheimer's disease. Alzheimers Dement. 2015;11:593-9.

21. Linard M, Letenneur L, Garrigue I, Doize A, Dartigues J-F, Helmer C. Interaction between APOE4 and herpes simplex virus type 1 in Alzheimer's disease. Alzheimers Dement. 2020;16: 200-8.

22. Burgos JS, Ramirez C, Sastre I, Valdivieso F. Effect of apolipoprotein $\mathrm{E}$ on the cerebral load of latent herpes simplex virus type 1 DNA. J Virol. 2006;80:5383-7.

23. Itzhaki RF, Lin W-R, Shang D, Wilcock GK, Faragher B, Jamieson GA. Herpes simplex virus type 1 in brain and risk of Alzheimer's disease. Lancet. 1997;349:241-4.

24. Itabashi S, Arai H, Matsui T, Higuchi S, Sasaki H. Herpes simplex virus and risk of Alzheimer's disease. Lancet. 1997;349:1102.

25. Beffert U, Bertrand P, Champagne D, Gauthier S, Poirier J. HSV1 in brain and risk of Alzheimer's disease. Lancet. 1998;351: 1330-1.

26. Beffert U, Bertrand P, Champagne D, Gauthier S, Poirier J. HSV1 and risk of Alzheimer's disease. Lancet. 1998;352:238.

27. Strandberg TE, Pitkala K, Eerola J, Tilvis R, Tienari PJ. Interaction of herpesviridae, APOE gene, and education in cognitive impairment. Neurobiol Aging. 2005;26:1001-4.

28. Barton N, Hermisson J, Nordborg M. Why structure matters. Elife. 2019;8:e45380.

29. Itzhaki RF, Lathe R, Balin BJ, Ball MJ, Bearer EL, Braak H, et al. Microbes and Alzheimer's disease. J Alzheimers Dis. 2016; 51:979.

30. Rathore N, Ramani SR, Pantua H, Payandeh J, Bhangale T, Wuster A, et al. Paired Immunoglobulin-like Type 2 Receptor Alpha G78R variant alters ligand binding and confers protection to Alzheimer's disease. PLOS Genet. 2018;14:e1007427.

31. Satoh T, Arii J, Suenaga T, Wang J, Kogure A, Uehori J, et al. PILRalpha is a herpes simplex virus-1 entry coreceptor that associates with glycoprotein B. Cell. 2008;132:935-44.

32. Matheoud D, Cannon T, Voisin A, Penttinen A-M, Ramet L, Fahmy AM, et al. Intestinal infection triggers Parkinson's diseaselike symptoms in Pink1-/- mice. Nature. 2019;571:565-9.

33. Mehta D, Jackson R, Paul G, Shi J, Sabbagh M. Why do trials for Alzheimer's disease drugs keep failing? A discontinued drug perspective for 2010-2015. Expert Opin Investig Drugs. 2017;26:735-9.

34. Itzhaki RF. Corroboration of a major role for herpes simplex virus type 1 in Alzheimer's disease. Front Aging Neurosci. 2018; $10: 324$. 